IOS Press

\title{
3D crack behavior in the orthopedic cement mantle of a total hip replacement
}

\author{
Abderahmen Sahlia $^{\mathrm{a}}$,Smail Benbarek ${ }^{\mathrm{a}, *}$, Steven Wayne ${ }^{\mathrm{b}}$, Bel-Abbes Bachir Bouiadjra ${ }^{\mathrm{a}}$ \\ and Boualem Serier ${ }^{\mathrm{a}}$ \\ ${ }^{a}$ Mechanics and Physics of Materials Laboratory, University of Sidi Bel Abbes, Cité Ben M'hidi, Sidi Bel Abbes, \\ Algeria \\ ${ }^{\mathrm{b}}$ University of Memphis, TN, USA
}

\begin{abstract}
The total hip replacement is an operation that replaces a diseased hip with a mechanical articulation. Both components of the mechanical articulation (stem and the cup) are bonded to bone using orthopedic cement, whose reliability determines the longevity of the implant. The cement around the metallic stem forms a mantle whose strength and toughness determine its resistance to fatigue and failure by fracture. Typical cements are acrylic polymers that often suffer from internal cracks and other defects created during polymerization. This study is a systematic analysis of preexisting $3 \mathrm{D}$ crack behavior in the orthopedic cement mantle when subjected to external body forces. Different crack orientations and angular positions around the mantle are studied to identify which locations will propagate the crack. This is accomplished by a global stress analysis of the mantle followed by a failure analysis. Amongst others, the existence of a crack in the proximal region of the orthopedic cement is identified as a critical area, especially in the lateral sides of the stem in the radial direction.
\end{abstract}

Keywords: Bone cement, crack, 3D Finite element analysis, total hip prosthesis, stress intensity factor, LEFM

\section{Introduction}

A total hip replacement (THR) is a joint implant that replaces the defective natural articulation. The main reason to proceed to this operation is to attenuate the hip pain due to the articulation arthros [1,2]. Figure 1 shows a schematic of the total hip prosthesis where the stem is fixed to the bone with orthopedic cement. Implants are very popular in the medical field, more than 800,000 hip replacements are performed annually $[3,4]$. Malfunctions over time are an accepted reality due to the deterioration of the orthopedic cement. In fact, the failure of the prosthesis cement in the absence of infection is the most recognized cause of the long term loosening of the prosthesis. When subjected to

\footnotetext{
*Corresponding author: Smail Benbarek, Mechanics and Physics of Materials Laboratory, University of Sidi Bel Abbes, BP 89, Cité Ben, M'hidi, Sidi Bel Abbes, 22000, Algeria. Tel.: +213 5543887 59; E-mail: sma_benbarek@yahoo.fr.
}

external loads such as impact and fatigue, the cement becomes the weakest part of the prosthesis due to its lower mechanical properties and brittle behavior. The failure of the cement occurs by the initiation and subsequent propagation of cracks which may initiate from stress concentrations in the front of micro-voids and cracks that initiate from the interfaces during polymerization [5-7]. Several studies [8-12] found that cracks within the bone cement may propagate under the cyclic loading during normal human activities. Topoleski et al. [13] report from fractography data that the primary in vivo failure mechanism of bone cement is fatigue. These studies provide evidence that the cement mantles fail by fracture from preexisting cracks and defects in the microstructure.

Numerous studies were carried out to investigate the probability of propagation of existing cracks in the cement. Murphy studied the distribution of the cracks in the cement mantle using a plate testing model [14]. 


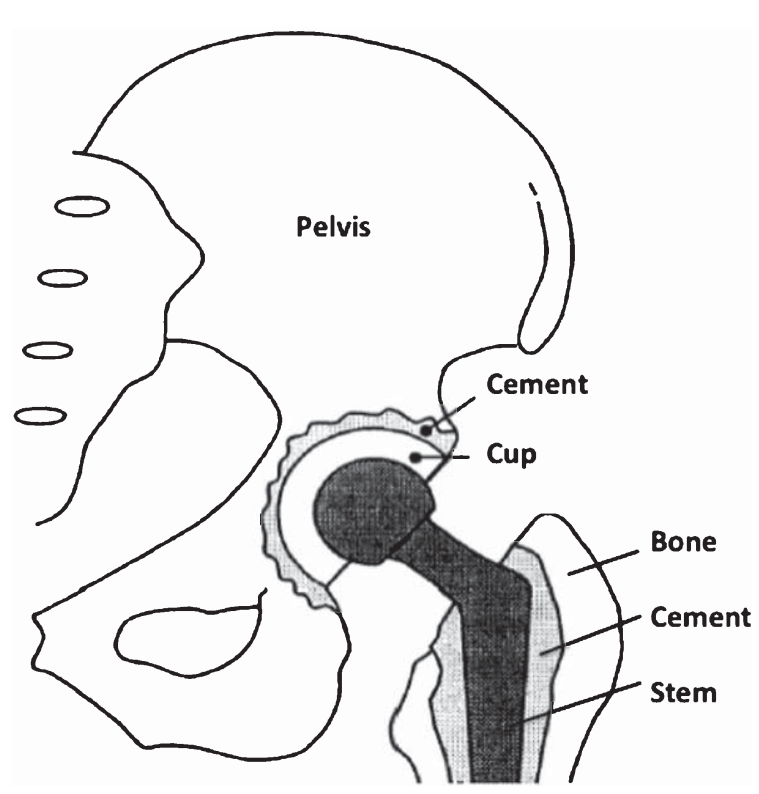

Fig. 1. A Schematic of the total hip prosthesis.

S. Benbarek and P.Nikolaus [15-17] analyzed the crack behavior in the cement mantle of the acetabulum part of the THR using a simplified 2D model. Also Flitti and Achour $[18,19]$ did the same analysis in the femoral part of the THR within the Sagittal plane. Byeongsoo and Stolk $[20,21]$ have done the same analysis in the transversal plan of the femoral part of the THR. The two-dimensional analysis of such phenomenon can only approximate the complexities of real 3D crack behavior within the cement. The complexity of the cemented hip's implant geometry and the out of plane loading on the joint needs to be included in the analysis to realize information close to the crack front in the third direction. While a significant challenge, the incentive to carry out 3D modeling of crack behavior and the compute stress intensity factors of three dimension crack in the cement is the ability to predict the cement mantle reliability from nondestructive inspection of implants such as high resolution microtomography that can reveal the presence of cracks in the cement [22].

To address this challenge we have conducted a three dimensional linear finite element analysis with subsequent crack analyses within the orthopedic cement mantle. The models are based upon anatomically accurate femoral hip components. The goal of this study is to analyze the behavior of a preexisting penny crack inside the orthopedic cement to predict the fracture risk
Table 1

Materials properties

\begin{tabular}{lcl}
\hline Materials & Young Modulus E (MPa) & Poisson ratio $v$ \\
\hline Cortical bone & 17000 & $0.3[0.01: 0.35]$ \\
Spongious bone & 2000 & $0.3[0.2: 0.5]$ \\
Bone Cement (PMMA) & 2300 & 0.33 \\
Metallic implant & 210000 & 0.30 \\
\hline
\end{tabular}

of the cement under the effect of the forces from human body weight. For this purpose, we calculate the stress intensity factor (SIF) on all nodes on the crack front in the proximal region of the cement. This use of linear elastic fracture mechanics allows us to predict the conditions that will cause a crack in the cement to grow. The obtained results from this study can help surgeons to predict whether or not an early THR loosening may occur based upon crack imaging techniques.

\section{Materials and methods}

\subsection{Materials}

The mechanical properties of the total hip prosthesis components are given in Table 1. The cortical bone, the spongious bone, the orthopedic cement and the stem are all considered as elastic isotropic materials [25-27].

\subsection{Modeling}

The 3D computer aided design (CAD) model of the human's femur is given by Pacific Research Labs [23]. The CAD model is composed of two regions: cortical bone and spongious bone. The three dimension reconstitution of both parts is realized separately and assembled. The Charnley-Muller-Kerboul third generation (CMK3) prosthesis is designed using the Solidworks Software [24] and includes the assembly of all parts of the prosthesis into one CAD model.

The prosthesis was positioned with respect to the femur to approximate the orientation commonly used in patients. Figure 2 shows a section of our reconstructed prosthesis model where the orthopedic cement has a uniform thickness of $2 \mathrm{~mm}$ around the implant, which serves to distribute the applied forces to the bone.

Figure 3 shows the femoral hip prosthesis model components: The stem (a), the cement mantle (b) the spongious bone (c) and the cortical bone (d). 


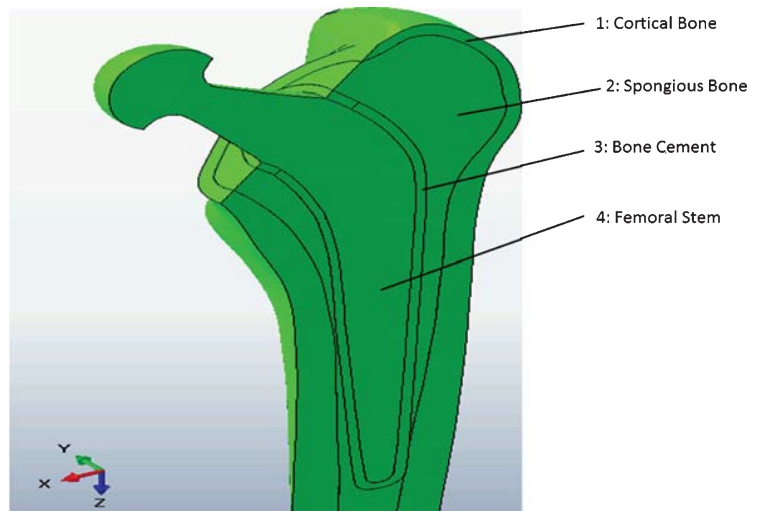

Fig. 2. Longitudinal section of the reconstructed prosthesis.

In this study we model a preexisting circular penny crack of $0.7 \mathrm{~mm}$ of diameter in the cement mantle. The evaluation of the fracture risk takes into account two parameters: (a) crack orientations and (b) angular positions around the mantle. We note that cracks can also initiate from interfaces and micro-voids and can be a thread of the THR integrity.

\subsection{Boundary conditions}

Pawels et al. found in their study of body forces on implants that the maximum force acting on the stem's head is 3 times the body weight [28]. Bergman confirmed these results when he studied 9 ordinary human activities of 4 persons where he found the maximum exerted forces acting on the head of the stem is about $300 \%$ of the human body weight [29]. He found using an instrumented prosthesis that the resulting force act-

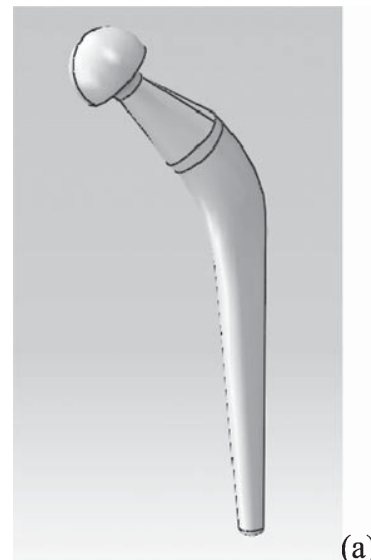

(a)

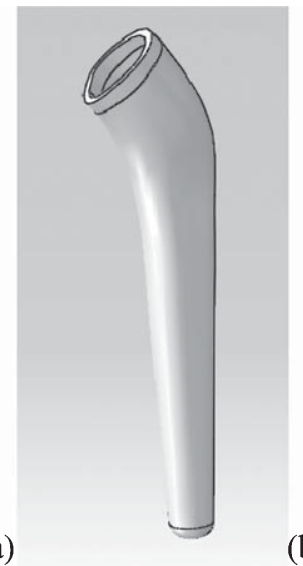

(b)

Fig. 3. The total hip components.

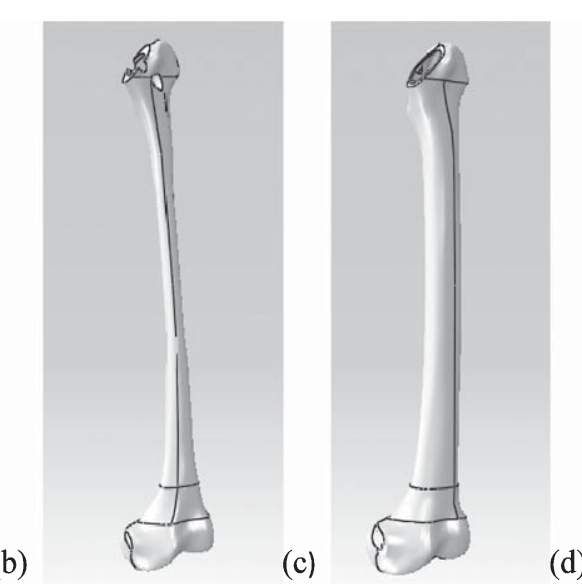

(c)
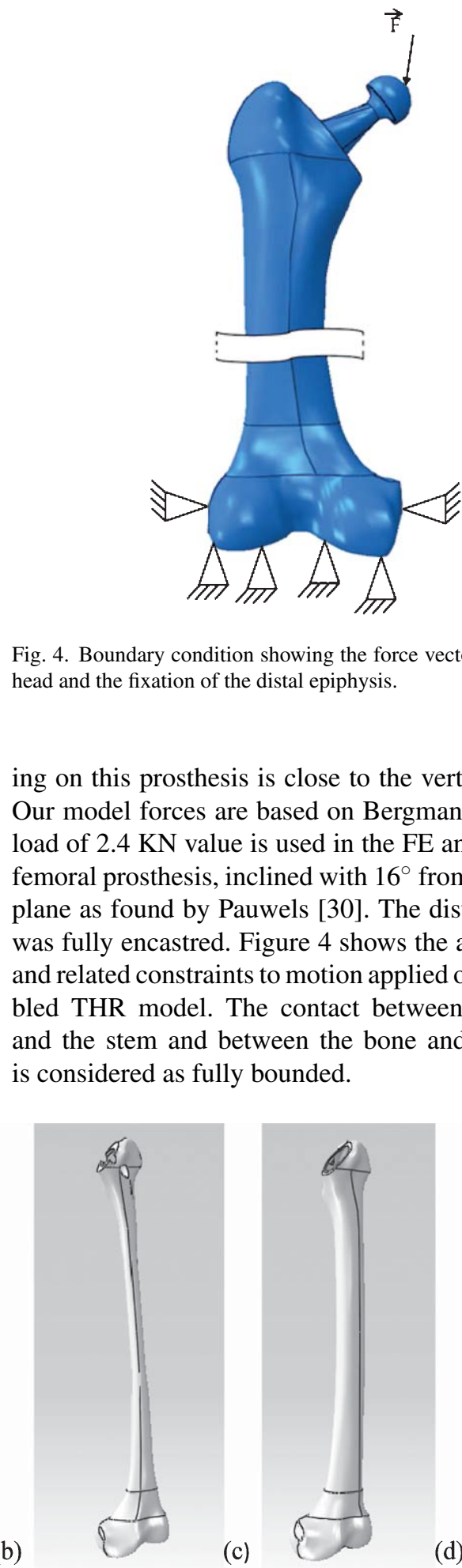

Fig. 4. Boundary condition showing the force vector acting on the head and the fixation of the distal epiphysis.

ing on this prosthesis is close to the vertical loading. Our model forces are based on Bergman results. The load of $2.4 \mathrm{KN}$ value is used in the $\mathrm{FE}$ analysis of the femoral prosthesis, inclined with $16^{\circ}$ from the Sagittal plane as found by Pauwels [30]. The distal epiphysis was fully encastred. Figure 4 shows the applied force and related constraints to motion applied on the assembled THR model. The contact between the cement and the stem and between the bone and the cement is considered as fully bounded. 


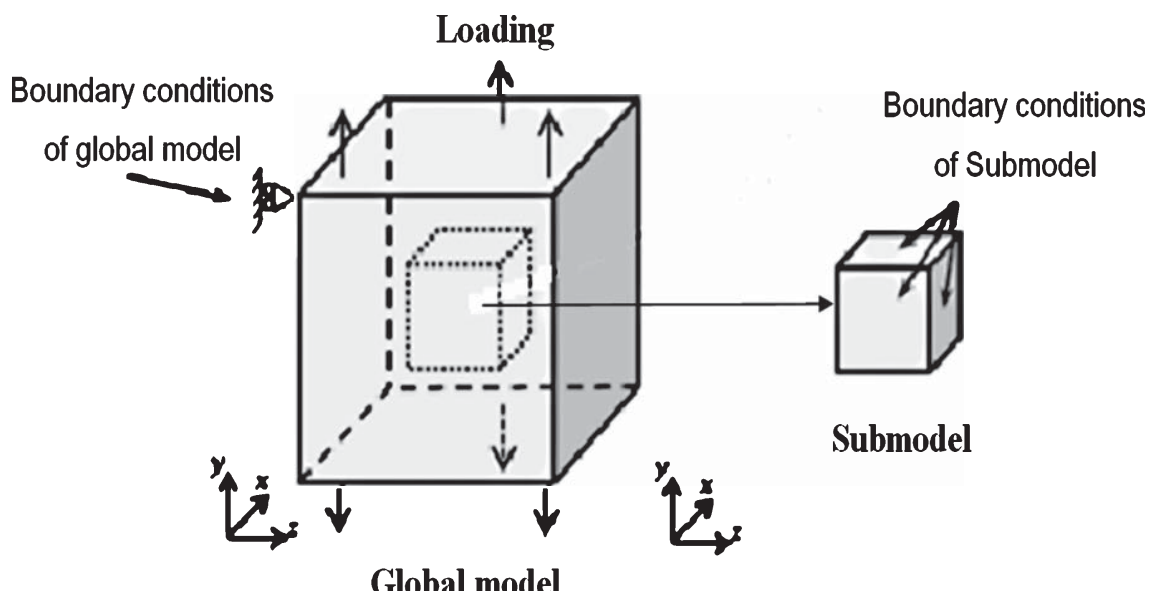

Fig. 5. Example schematic of a global model and submodel. The computed displacements on the global model are interpolated on the submodel boundaries.

\subsection{Sub-modeling technique}

The sub-modeling analysis technique included with Abaqus Software is used to compute the stress intensity factors around the crack front [31]. This technique allows us to produce highly refined meshing around the crack front, vary the positioning of the crack in the cement mantle and save computing resources. Using this technique, the complete model is divided in two distinct models: a global model and submodel (Fig. 5). The global model contains the total geometry, the loading conditions and boundary conditions. The submodel is specified as an arbitrary part taken from the global assembled model and holds the characteristics of the global model including the original coordinate system and material properties.

The global model is analyzed first to get the global response of the global model to the applied boundary conditions. In the submodel, the solution from the global model is interpolated at the submodel surface using an appropriate interpolation function. The submodel can be analyzed separately using the global model response. The link between both models is defined at the intersection surfaces with boundary conditions applied on the submodel. Two approaches exist in Abaqus to do this connection: node based connection and surface based connection. The SIF related to the energy release rate ( $\mathrm{J}$ integral) computed by the software [32].

Figure 6 shows the submodel designed to analyze the crack behavior in the cement (The global model is the cement). We chose this technique to reduce computational time and hardware resources and to simplify changes in the position of the submodel or its orientation.

In this study; 8 crack positions are chosen around the circumference of the cement collar. For each position, the crack is rotated around its $y$ axis with a step of $15^{\circ}$ as showed in Figs. 6 and 7. The purpose of this is to predict the likelihood of propagating a preexisting crack in the cement mantle. We accomplish this goal by positioning the $3 \mathrm{D}$ penny crack at different circumferential positions identified as regions where the highest combination of stresses occurs in the cement mantle.

\subsection{Mesh}

The determination of stress intensity factor at the crack tip requires a highly refined mesh with proper element selection (C3D20) to gives results close to the reality. In fact, the cement is a determinant element of the prosthesis and the refinement of its mesh is of great importance for the structure analysis. Figure 8 shows the mesh of the total hip prosthesis different components. This figure shows a highly refined mesh around our studied area, the proximal region, to provide a good approximation of the displacement in the vicinity of the sub-model's region and to calculate the stress intensity factors. The surrounding mesh of the crack front must be specially meshed as showed in Fig. 9. The mesh is done using hexahedral quadratic element (C3D20) for the area of interest and tetrahedral quadratic element (C3D10) for the remaining parts of the THR. 


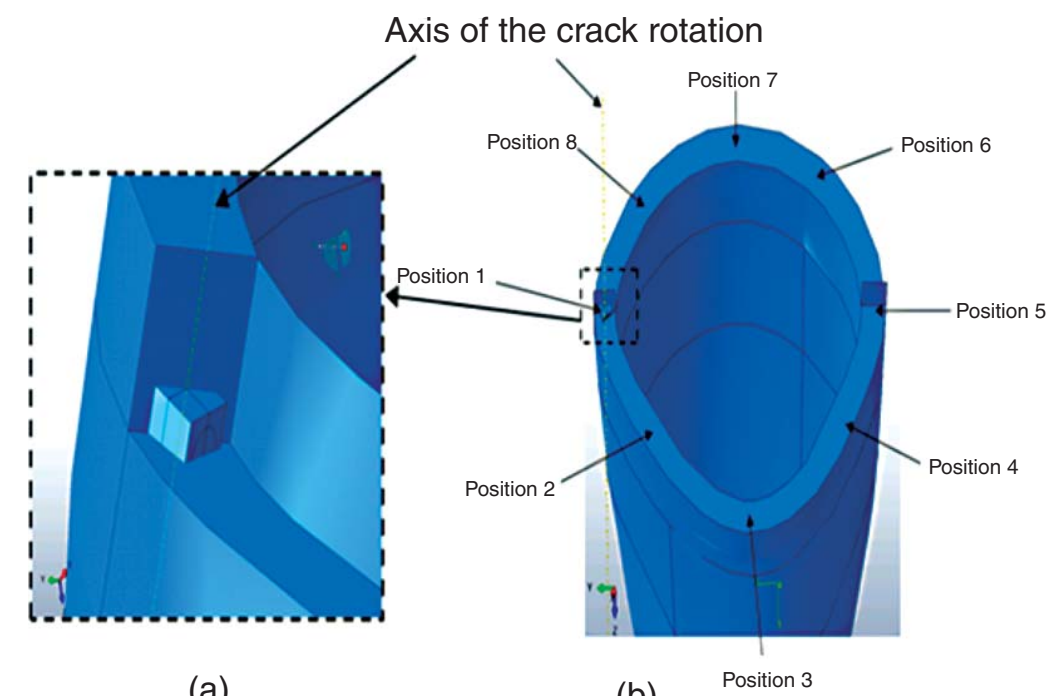

Fig. 6. (a) Close-up the crack submodel in the cement mantle and (b) the crack positions.

(a)

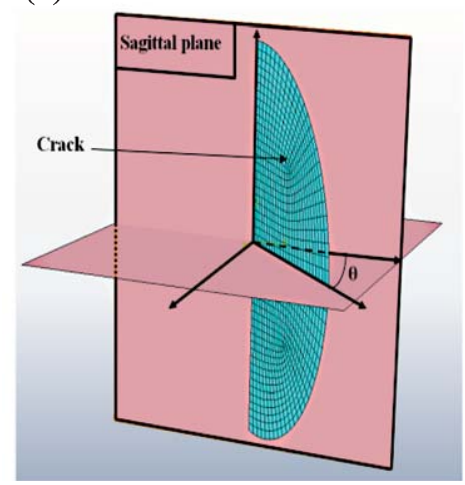

(b)

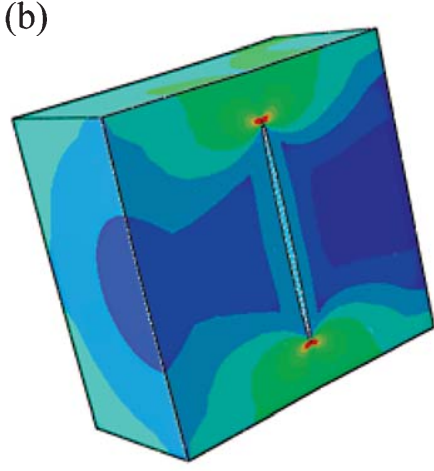

Fig. 7. (a) the crack rotation angle and (b) the opened crack within the submodel.
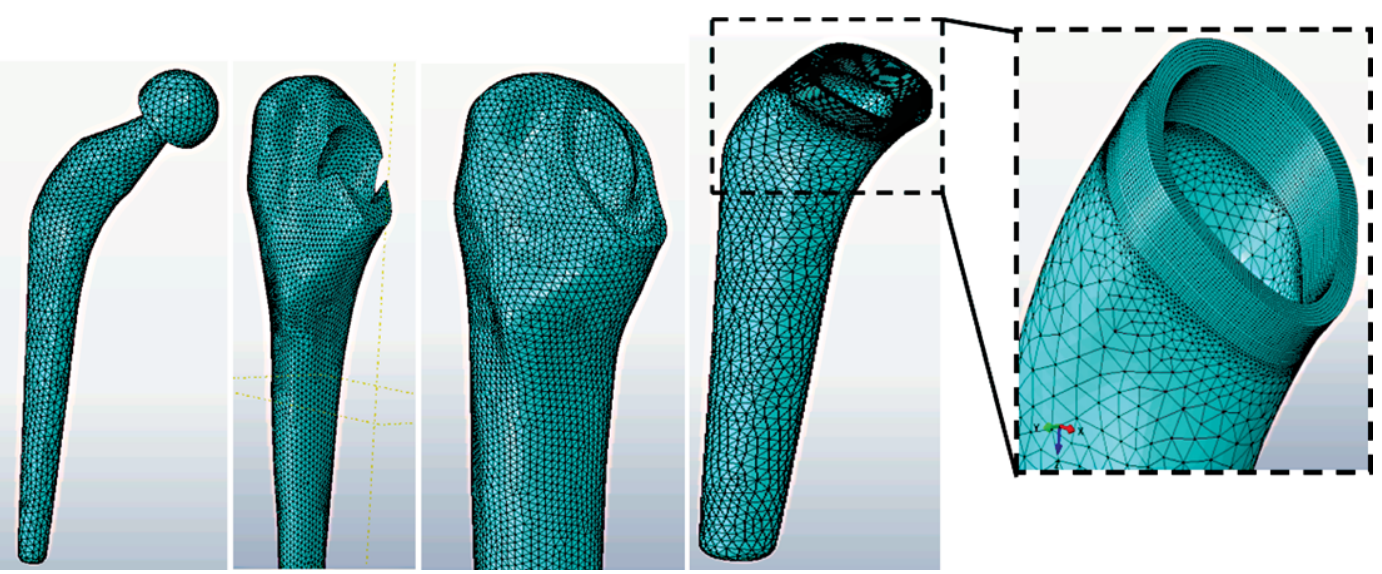

Fig. 8. Mesh of the different parts of the THR with refined meshing of the proximal region of the cement. 


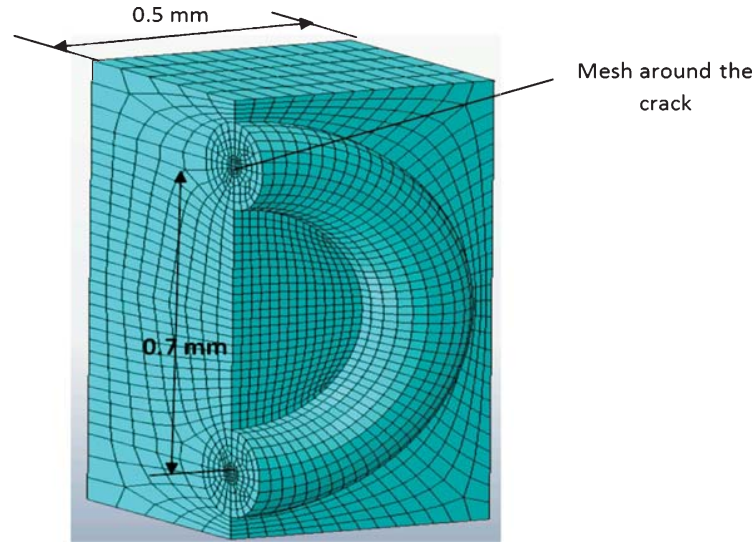

Fig. 9. Refined mesh around the crack front.

\section{Results}

The results are organized to first present equivalent, radial and circumferential stresses that developed in the mantle of the global model, and then we follow with findings concerning the presence of a crack at different positions within the high stress regions of the mantle.

\subsection{Stress distribution in the cement mantle}

\section{Equivalent Stress distribution}

The analysis of the stress distribution in the cement mantle allows us to find the zones of highest stress and then compute the risk of failure of these zones by computing the stress intensity factors that could contribute to the initiation or opening of a crack. The distribution and magnitude of equivalent stress in the cement is shown in Fig. 10. Two high stress regions occur where the cement is in direct contact with the cortical bone.

\section{Radial stress}

Since the cement behaves differently under tension and compression (50 MPa under compression and 25 MPa under tension), we chose to analyze the distribution of the normal stresses in a cylindrical coordinate system to know the nature and the level of the normal stresses in the cement mantle.

Figure 11 shows the radial stress distribution and its magnitude in the cement mantle. In this figure one notices that the cement is subjected to compression stresses of about $16 \mathrm{MPa}$ and creates a localized region of cement in tension of about $17 \mathrm{MPa}$ on the contact edge with the spongious bone.

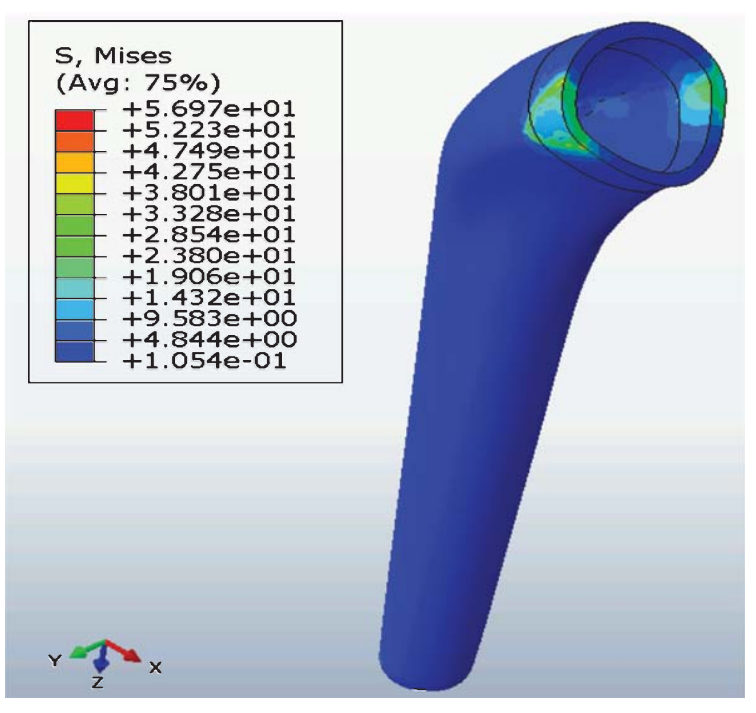

Fig. 10. Equivalent stress (MPa) distribution in the cement mantle.

\section{Circumferential stress}

Figure 12 illustrates the circumferential stress and its amplitude in the orthopedic cement. Opposite to the radial stress case, the circumferential shows increased tension in the majority of the proximal area of the cement. The cement is highly stretched along its contact area with the bone, which makes the closest area in circumferential tension.

\subsection{Crack behavior in the cement mantle}

Firstly, the behavior of a crack situated in the proximal region of the cement mantle at the left side (position 1 Fig. 6) was studied. The analysis was done for multiple orientations of the crack as showed in Fig. 7. Figure 13 shows the variation of the stress intensity factor $\mathrm{K}_{\mathrm{I}}$ on the crack front with respect to the crack orientation. For the purposes of our study, negative values of the stress intensity factor are interpreted to mean that the crack is closed, while positive values indicate crack opening, thus we find the crack in Fig. 13 is entirely opened when it is inclined between $90^{\circ}$ and $180^{\circ}$. The crack is symmetrical, so its analysis is done for just a half of a circle $\left(0^{\circ}\right.$ to $\left.180^{\circ}\right)$. The stress intensity factor is relatively constant along the crack front (see Fig. 13). The most dangerous crack position is $130^{\circ}$; as this gives the maximum $\mathrm{K}_{\mathrm{I}}$ value equivalent to $6.06 \mathrm{MPa} \sqrt{\mathrm{mm}}$. This position gives the highest values of $\mathrm{K}_{\mathrm{I}}$ because of the effect of the stress around the crack which makes it in tension and opens it. 

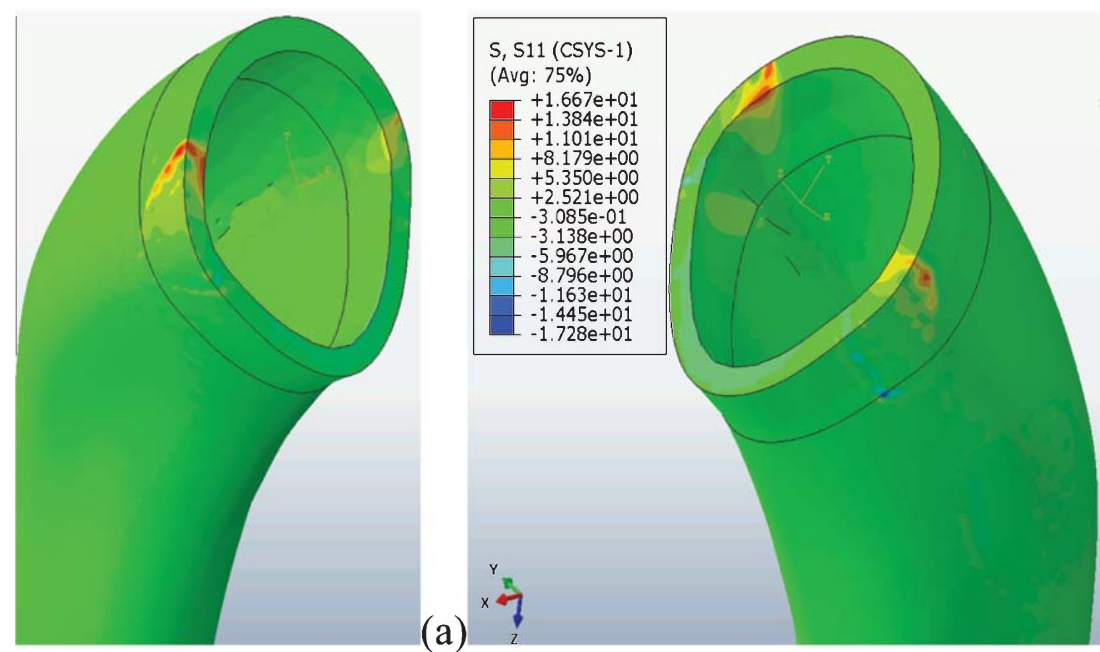

(b)

Fig. 11. (a) Right view and (b) left view of the radial stress (MPa) distribution in the cement mantle. The red color indicates the highest tensile stress. (Colours are visible in the online version of the article; http://dx.doi.org/10.3233/ABB-140097)
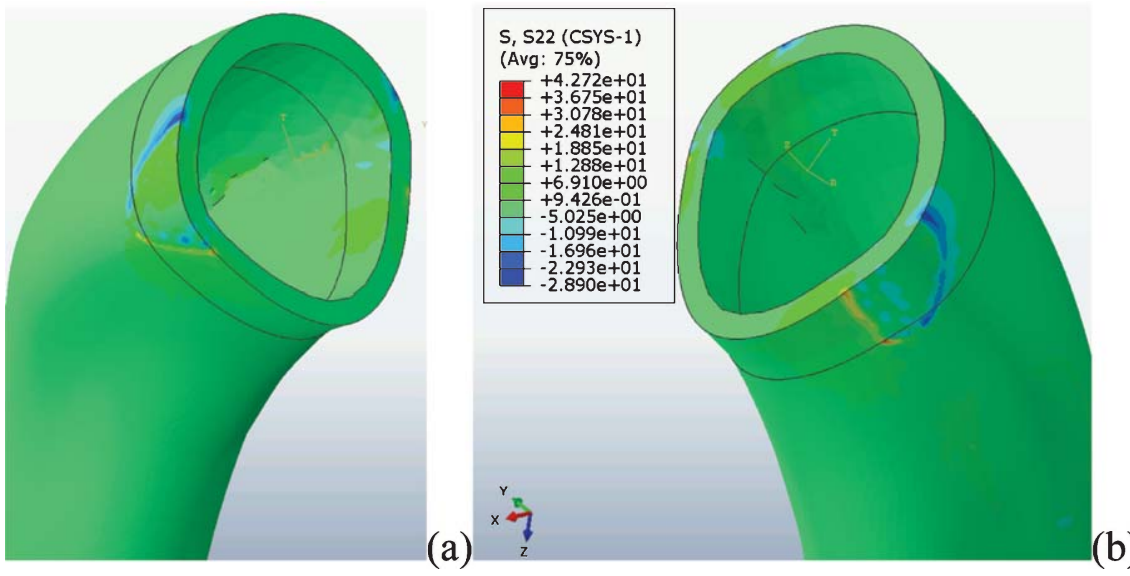

Fig. 12. (a) Right view and (b) left view of the circumferential stress (MPa) distribution in the cement mantle.

Figure 14 shows the equivalent position of $130^{\circ}$ and the range in which this crack is open and subjected to propagation. Over this range the crack is closed and may not propagate due to compressive stresses.

Figure 15 is show the distribution of the stress intensity factor in mode II with respect to the crack orientation. The negative values of the mode I stress intensity factors indicate the crack is closed. The results show an anti-symmetric curves since the entire crack front is subjected to the same shear, the moiety of the crack is sheared in one way with the other being opposite. The shearing of the crack is more important in that it generates a relatively high value of stress intensity factor $(7.07 \mathrm{MPa} \sqrt{\mathrm{mm}})$. Both sides of the crack

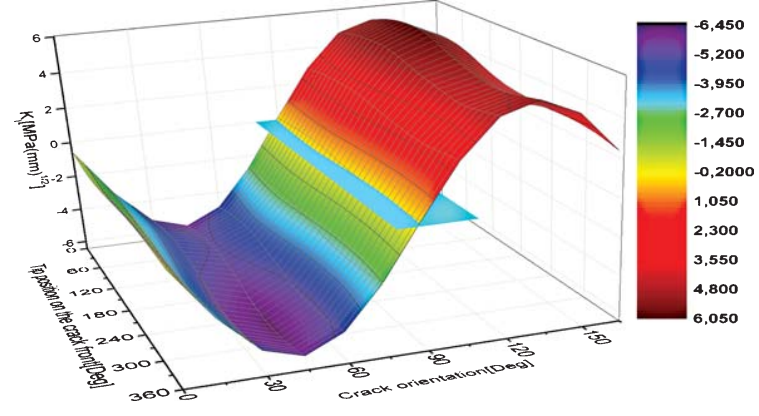

Fig. 13. $\mathrm{K}_{\mathrm{I}}$ distribution on the crack front as function of the crack orientation in the pos 1 in cement mantle. Above the plane indicates the opening of the crack. 


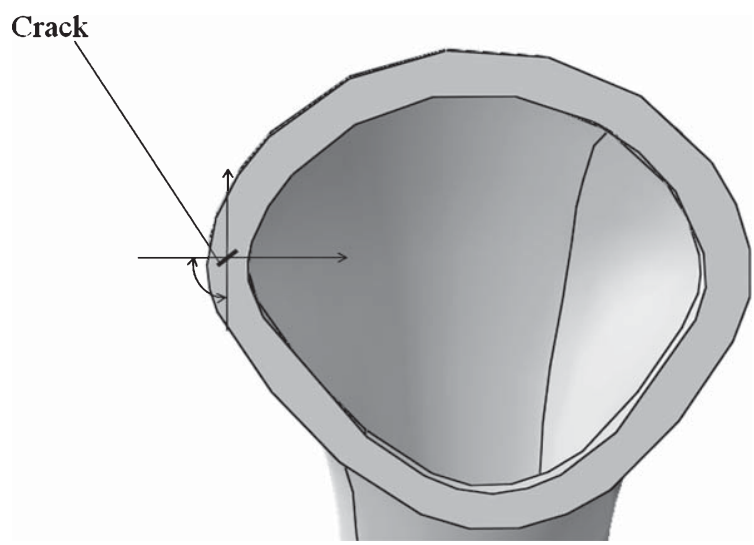

Fig. 14. The crack critical position and the range in which the crack is open.

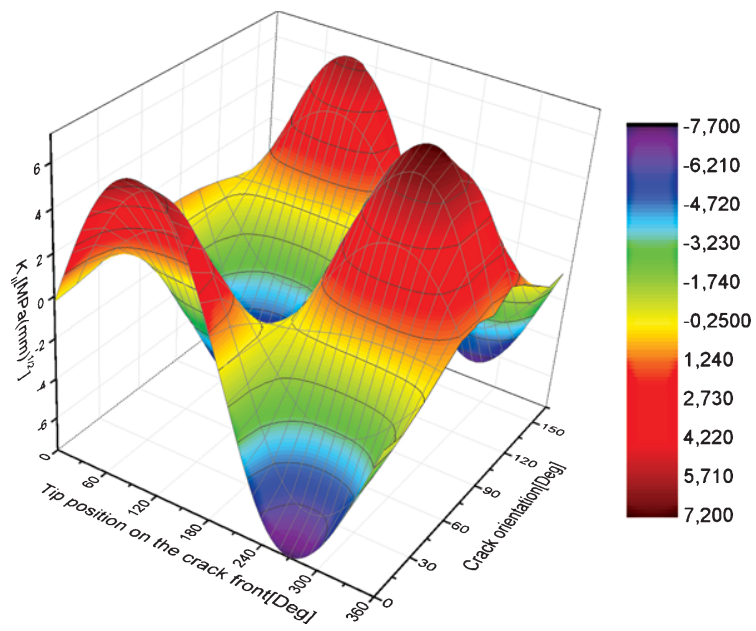

Fig. 15. $\mathrm{K}_{\mathrm{II}}$ distribution on the crack front as function of the crack orientation in the pos 1 in cement mantle.

are subjected to such intensity but are shifted by $45^{\circ}$. The combination of two crack opening modes of the crack can be more dangerous than under a single mode. The propagation of the crack can be predicted for both modes in this range.

The distribution of the stress intensity factor in mode III is shown in Fig. 16 and plotted with respect to the crack orientation. This figure clearly shows that the crack results are also anti-symmetric. We concern ourselves with the results of $\mathrm{K}_{\mathrm{III}}$ in the range $\left[90^{\circ}, 180^{\circ}\right.$ ] because of the crack closure out of this range. One can notice that the mode III has values of the stress intensity factor between 5.2 $\mathrm{MPa} \sqrt{\mathrm{mm}}$ and $-5.2 \mathrm{MPa} \sqrt{\mathrm{mm}}$. The maximum value of $\mathrm{K}_{\mathrm{III}}$ corresponds also to the

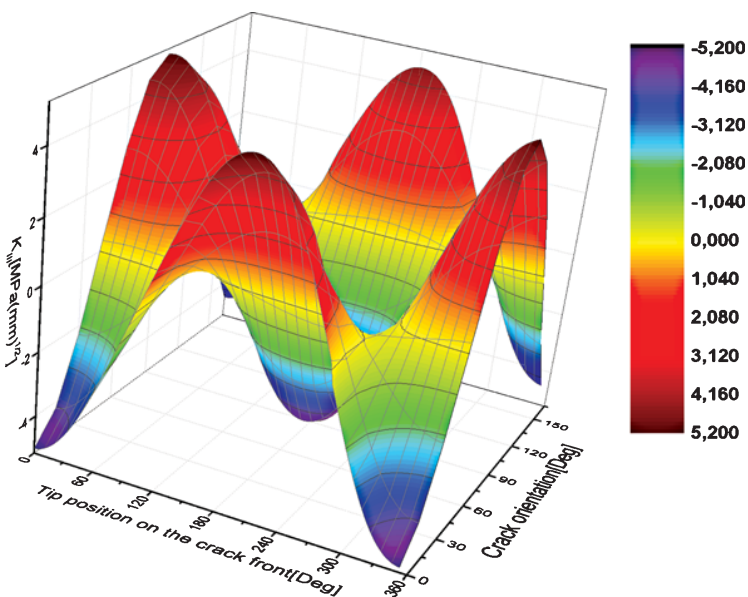

Fig. 16. $\mathrm{K}_{\mathrm{III}}$ distribution on the crack front as function of the crack orientation in the pos 1 in cement mantle.

maximum values of $\mathrm{K}_{\mathrm{II}}$ on the same crack front. This condition may occur in both modes when the crack exists on the edge of the crack opening range, and may propagate the crack in a combined mode.

\subsection{Comparison of different crack positions}

$>$ The crack opening mode $\mathrm{I}\left(\mathrm{K}_{\mathrm{I}}\right)$

We now consider multiple crack positions in the cement mantle to do a comparison between the positions shown in Fig. 6 and present the findings in Fig. 17 for mode I stress intensity factors as a function of crack orientation and position in the mantle.

One notices that positions 1 and 5 give the most important $\mathrm{K}_{\mathrm{I}}$ values, so the crack at these positions will likely propagate. When the crack is at the position 5 it gives positives values of the $\mathrm{K}_{\mathrm{I}}$ when its rotation is between $30^{\circ}$ and $120^{\circ}$. We observe that this position is the opposite of position 1 , so it gives the similar values but in the opposite direction. The position 1 and 5 are the most dangerous positions that the crack can be located, as may lead to the collapse of the cement mantle by the propagation of an existing crack at these two positions. For the remaining positions (position: 2,3,4,6, 7 and 8) there is no risk of crack propagation or it is very low, because of the low or negative values of the stress intensity factors. In fact, the cement is under compression even in position 8 , creating a situation where the bone is pulled by the cement at both sides (pos1 and pos5) which effectively compresses the cement in the vicinity of position 

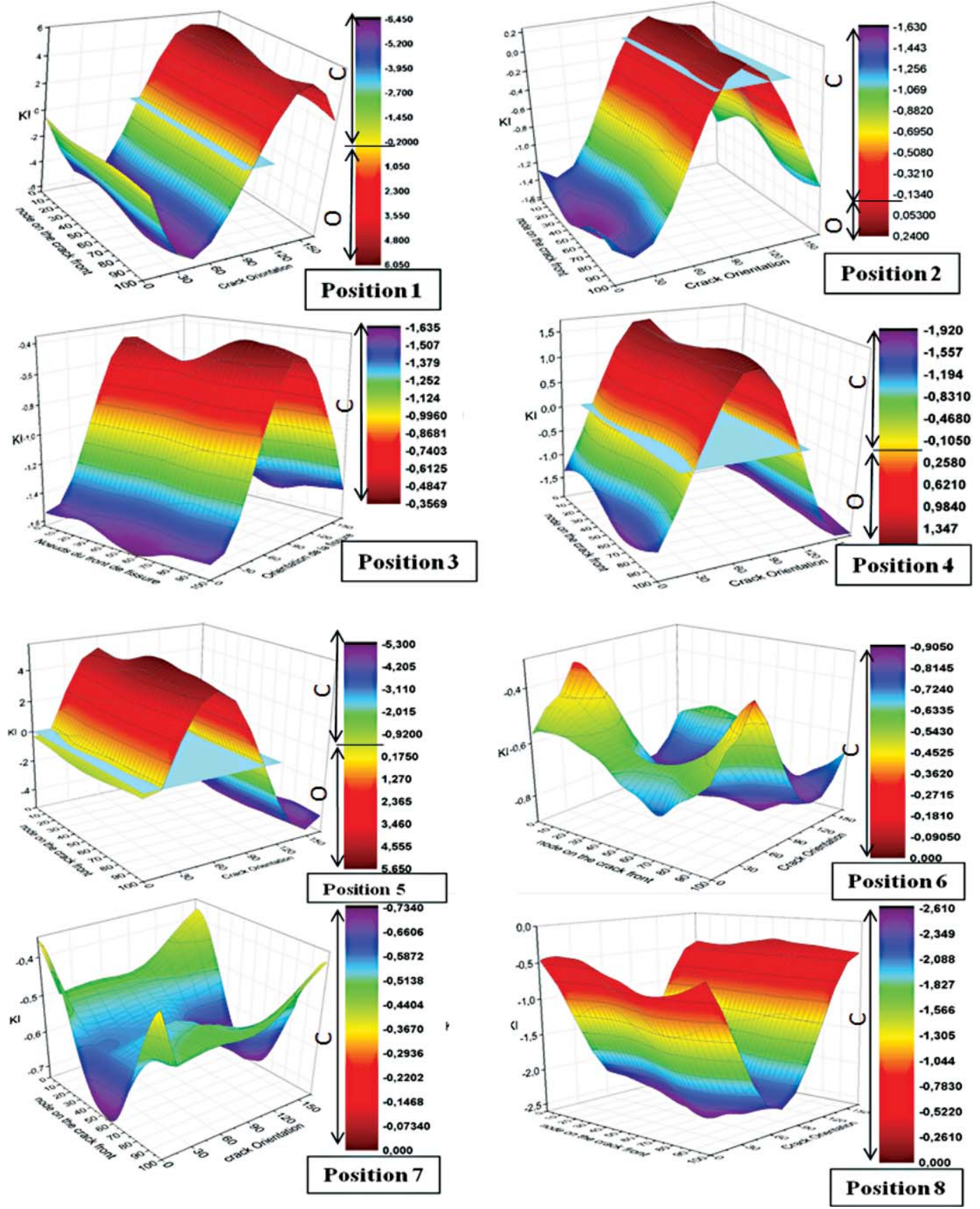

Fig. 17. $\mathrm{K}_{\mathrm{I}}$ comparison for different crack locations (C: indicates the crack closing range and $\mathrm{O}$ : indicates the crack opening range).

8. In Fig. 18 we present the range in which the crack is opened and it's most critical orientation within this range for the four positions when the crack is able to propagate.
The crack opening mode II and III $\left(\mathrm{K}_{\mathrm{II}}\right.$ and $\left.\mathrm{K}_{\mathrm{III}}\right)$ :

Figures 19 and 20 show the mode II and mode III crack opening stress intensity factor between the 4 


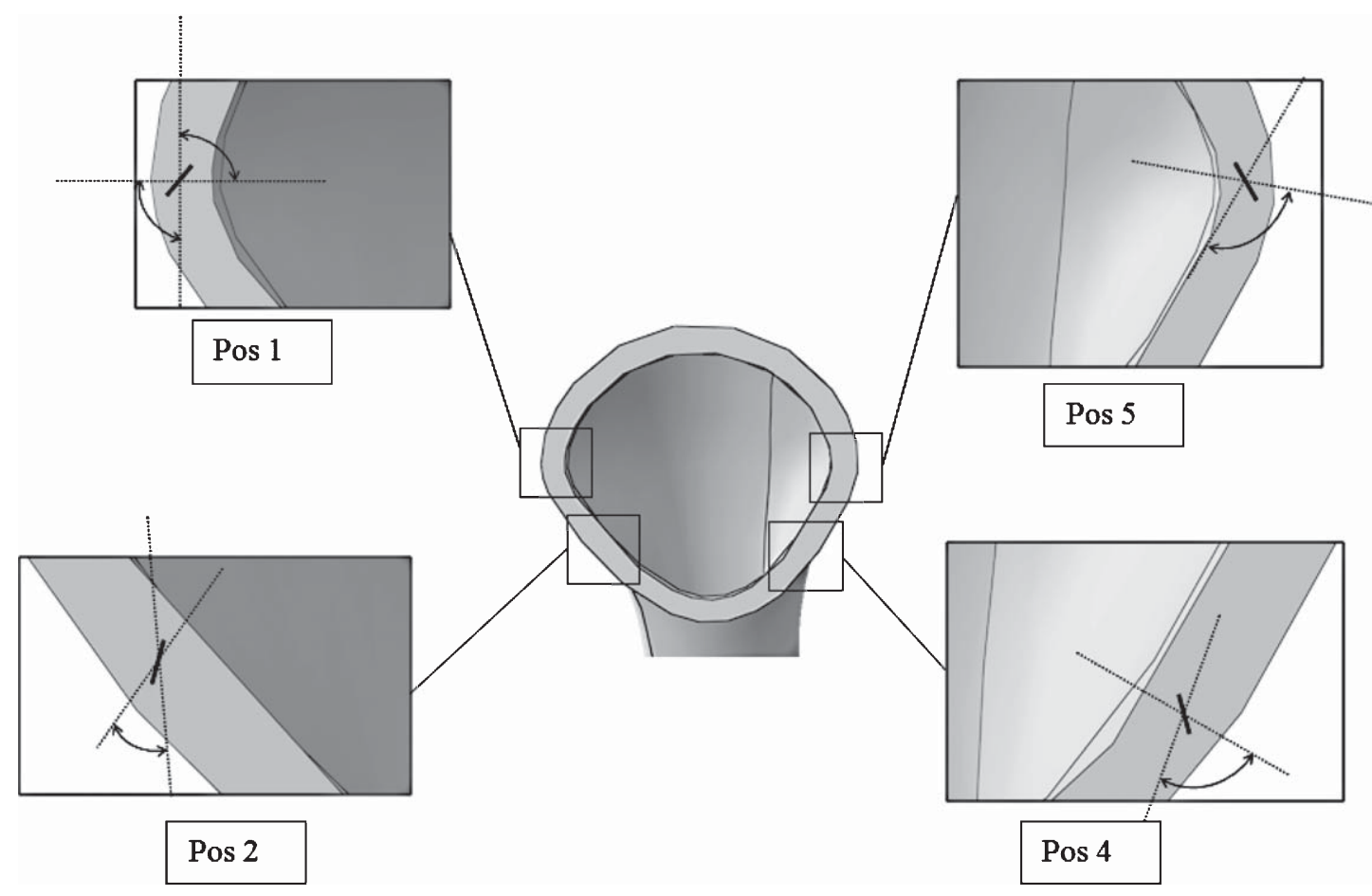

Fig. 18. Figure showing the most critical crack orientation within opening range $\left(\mathrm{K}_{\mathrm{I}}>0\right)$ for each position.

crack positions in which the crack is open. Like noticed previously on the $\mathrm{K}_{\mathrm{I}}$ curves, the critical positions are almost the position 1 and position 5 . The crack is under one way shearing, so its gives two opposite $\mathrm{K}_{\mathrm{II}}$ Values. Both halves of the crack are sheared in opposite ways. The stress intensity factor $\mathrm{K}_{\text {III }}$ takes an opposite attitude of the mode II on the same crack front(when $\mathrm{K}_{\mathrm{II}}$ is $\max$ the $\mathrm{K}_{\mathrm{III}}$ is min and vice-versa). Figure 21 shows the most critical crack orientations within the range when the crack is open.

\section{Discussion}

Regarding our stress analysis, we can explain the concentration of equivalent stresses by the fact that the mainstream of the load transfer crosses these areas from the stem toward the bone. One notices also that the maximum stress registered is higher than the elastic limit of the cement $(25 \mathrm{MPa})$ in some small zones close to the intersection point between the cement, the spongious bone and the cortical bone, due to the complexity of the geometry (sharp angle at the intersecting point). These localized phenomena cannot affect the whole distribution of the stresses in the cement mantle. In the remaining regions of the cement, the stress values are very low (less than $4 \mathrm{MPa}$ ) compared with the limits of fracture of the cement. So the presence of a crack in these areas may lead to propagation. T.P Cullelon found a great amount of defect (cracks) close to the proximal surface after a fatigue test, which supports our results [33]. Concerning the radial stress distribution in Fig. 11, we found that the existence of a crack perpendicular to the radial direction in the proximal zone of the cement may not be a threat for the failure of the cement because above and below these areas the cement is in contact with the spongious bone which is a soft material compared to the cement and/or the cortical bone. In the remaining part of the cement the stress level is relatively low. The analysis of the distribution of the circumferential $\left(\sigma_{\theta \theta}\right)$ stress allows us to deduce that the existing crack, perpendicular to the circumferential direction within the circumferential stress field, will open it and if the load increases it may propagate following the radial direction.

Our analyses of crack behavior in the proximal region of the mantle have identified specific crack orientations and circumferential locations that may lead to the crack propagation. K. A Mann found that only existing of radial cracks in the proximal region of 

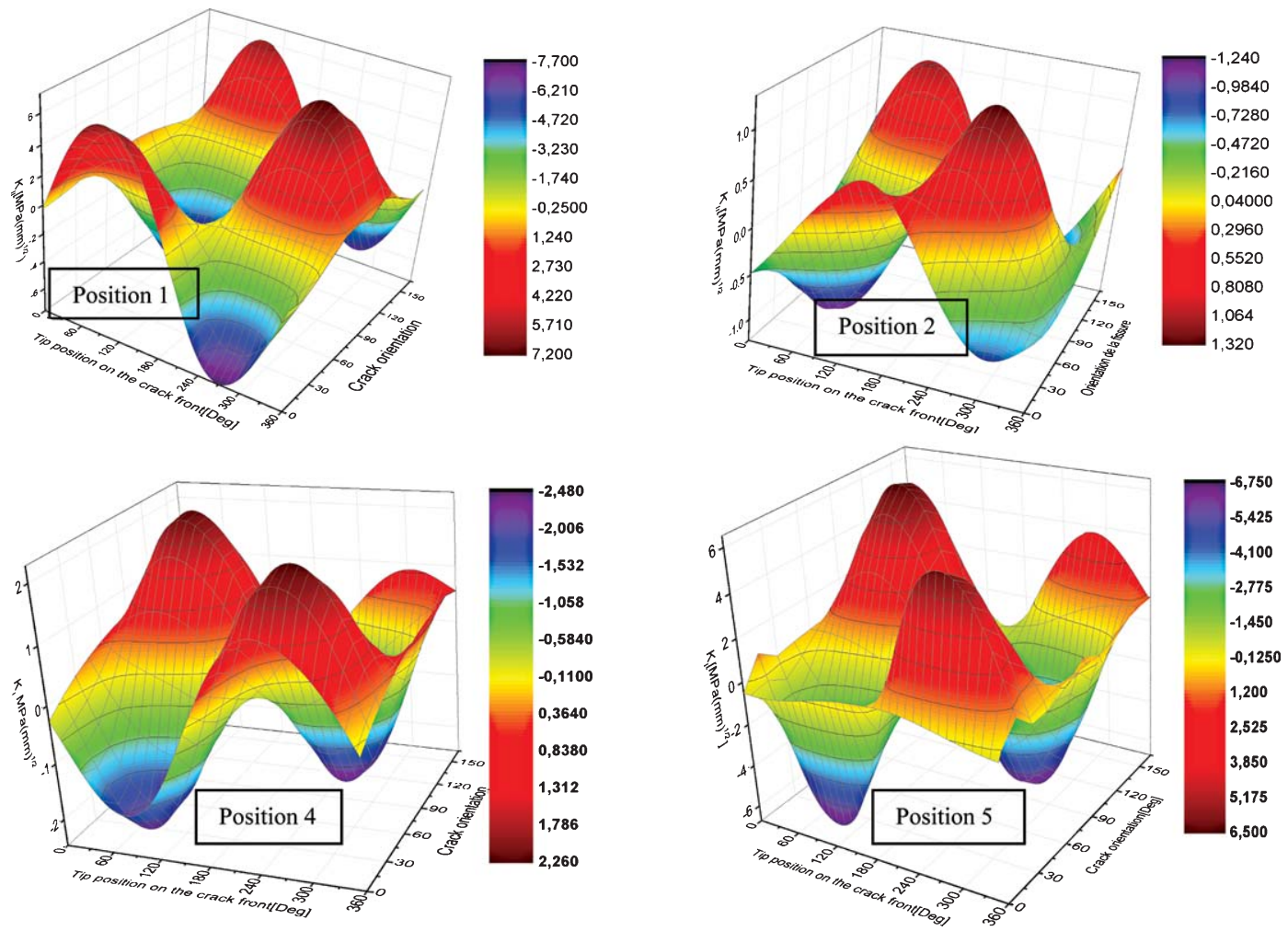

Fig. 19. $\mathrm{K}_{\mathrm{II}}$ comparison for the four locations where the crack is open.

cement mantle could propagate [34]. Murphy found in their experimental study that the cracks propagation directions are distributed normally about the direction perpendicular to the applied load [14]. These independent studies both provide findings that support our results.

When analyzing the second and the third crack opening mode curves (Figs. 19 and 20) we find that the maximum $\mathrm{K}_{\mathrm{II}}$ value is out of crack opening range. We anticipate that the most dangerous crack orientations occur at the outer bounds of the range (Fig. 21).

\section{Conclusions}

The cement mantle is a determinant element of the THR and its reliability is of great importance for the estimation of the lifespan of the prosthesis. In this study, we have shown the effects of a preexisting crack and its likelihood to propagate in the cement mantle through a detailed analysis employing a 3D finite element model of a total hip prosthesis. Our results may help clinical staff predict a prior THR loosening if they notice, post operation, the existing of cracks in concordance with our results. The obtained results allow us to deduce the following conclusions:

- The orthopedic cement is highly stressed at the areas when it is in contact with the cortical bone. The sealing condition, which is: The positioning of the implant in the femur and the contact between the different components can play an important role on the stress distribution in the cement and consequently the stability of prosthesis. In our study, the contact between the cement and the cortical bone concentrates the stresses in the cement on the edges of this contact.

- When the crack exists in the proximal region of the cement in both lateral sides and when its orientation is between $90^{\circ}$ and $180^{\circ}$ from the Sagittal plane for the first crack and between $30^{\circ}$ and $120^{\circ}$ for the second crack; it is open $\left(\mathrm{K}_{\mathrm{I}}>0\right)$ and its propagation is most probable. 

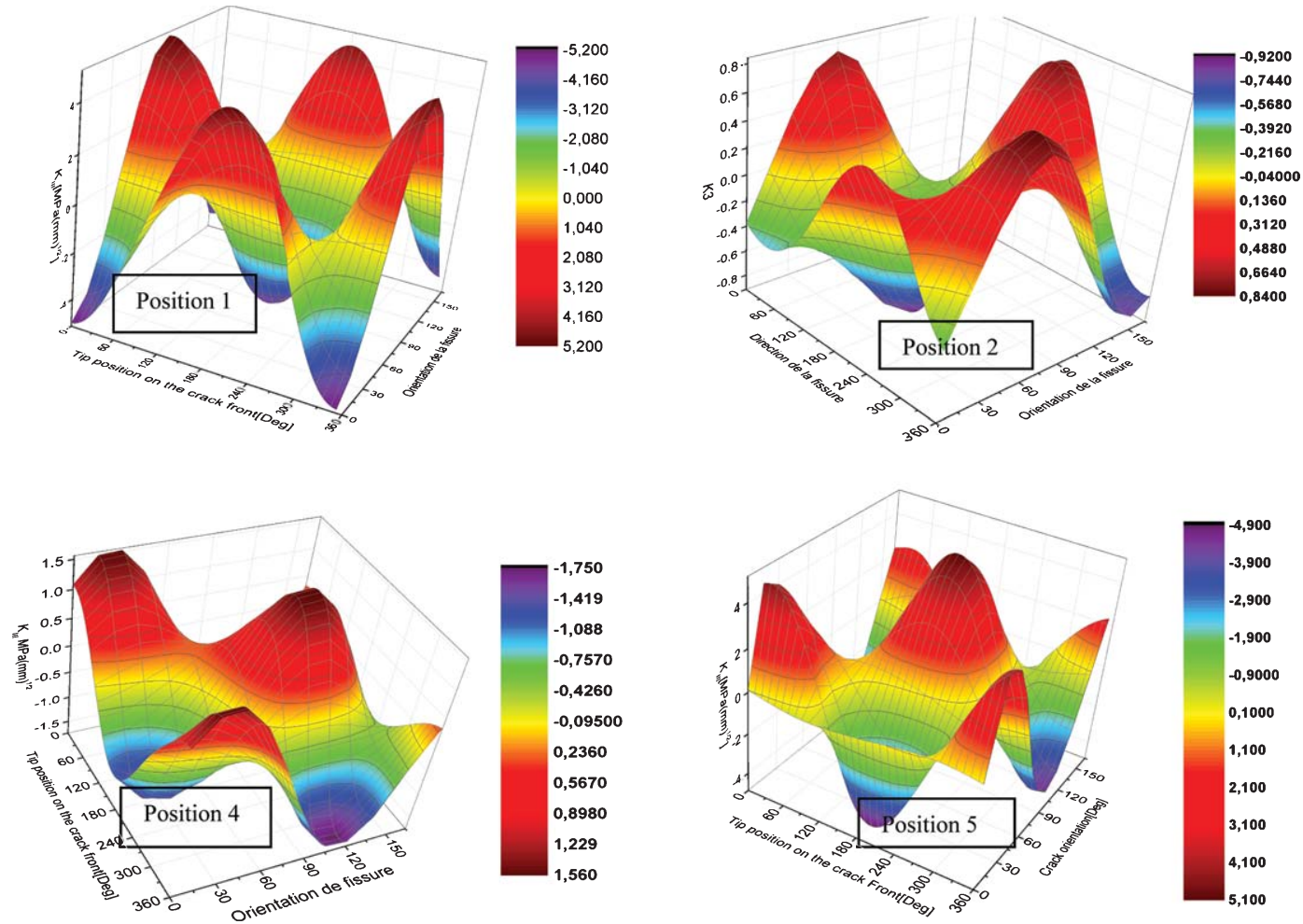

Fig. 20. $\mathrm{K}_{\mathrm{III}}$ comparison for the four locations where the crack is open.

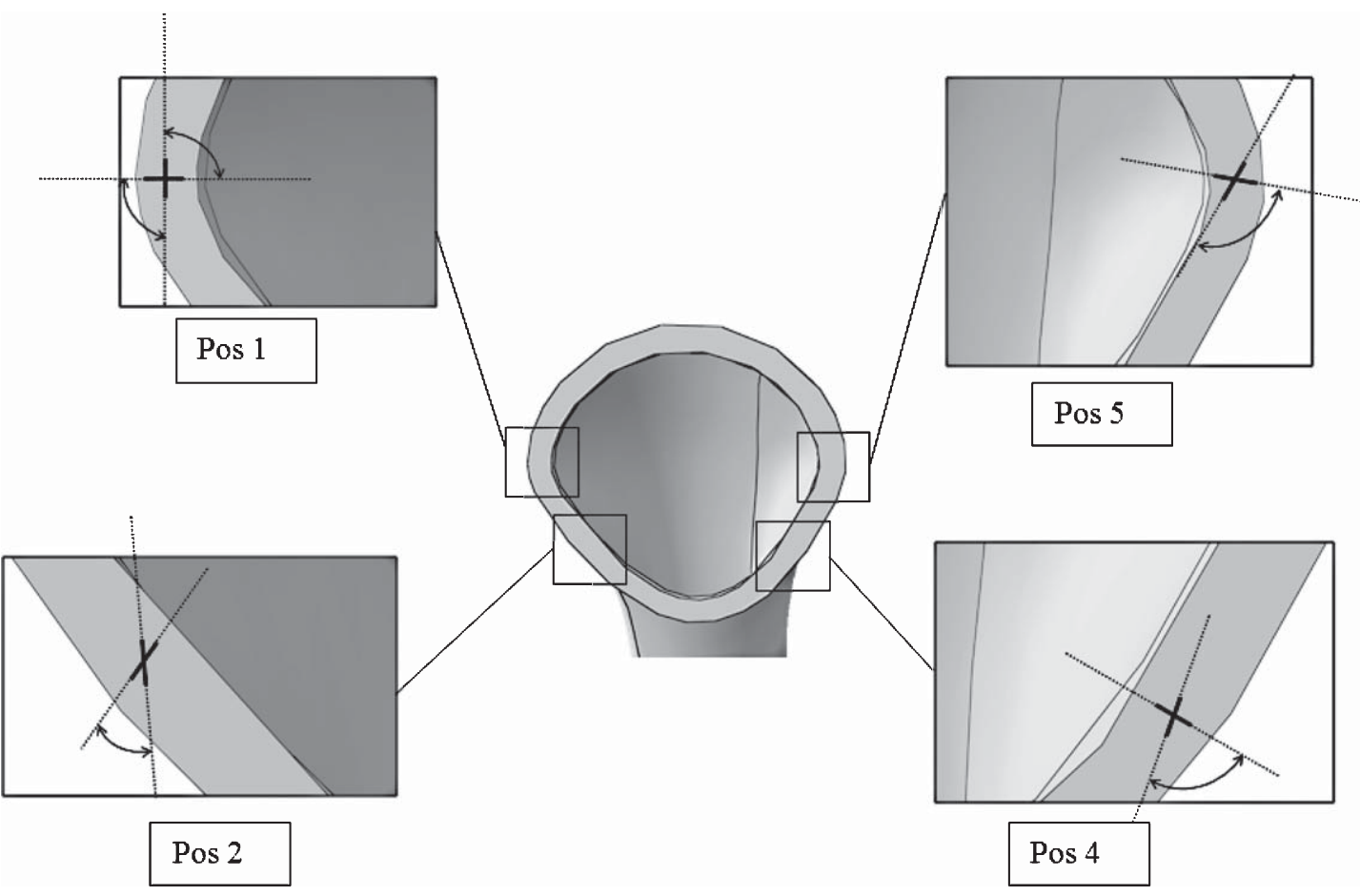

Fig. 21. Figure showing the most crack (mode II and III) critical orientations (two) in the crack opening range $\left(\mathrm{K}_{\mathrm{I}}>0\right)$ ). 
- The most critical orientations which make the crack likely to propagate in mode II and III, lies on the outer limits of the crack opening range.

- The crack at these positions may propagate under combined of all 3 modes of propagation,

- If the crack exists in the proximal zone in the remaining positions, it is in closed state, so it does not make any threat for the cement failure.

\section{References}

[1] C. Naudin and N. Grumbach, Larousse medicale, Larousse, 2002.

[2] F. Pauwels, Atlas zur Biomechanik der gesunden und kranken Hüfte. Springer Verlag, Berlin, 1973.

[3] M. Jasty, W.J. Maloney, C.R. Bragdon, D.O. O'Connor, T. Haire and H.H. Harris, The initiation of failure in cemented femoral components of hip arthroplasties, J Bone Joint Surg Br 73B (1991), 551-558.

[4] W.J. Maloney, J. Murali, D.W. Burke, D.O. O'Connor, C. Zalenski and E.B. Braydon, Biomechanical and histologic investigation of cemented total hip arthroplasties, Clin Orthop Rel Res 249 (1989), 129-140.

[5] R. Huiskes, Failed innovation in total hip replacement, Acta Orthop Scand 64 (1993), 699-716.

[6] B.P. Murphy and P.J. Prendergast, On the magnitude and variability of the fatigue strength of acrylic bone cement, Int J Fatigue 22 (2000), 855-864.

[7] P. Pernod, F. Herlemont, M. Khelkhal, J. Legrand and P. Hernigou, Laser et ciment, Actualités en biomatériaux, Romillat, Paris 3 (1996), 257-260.

[8] K.A. Mann, S. Gupta, A. Race, M.A. Miller, R.J. Cleary and D.C. Ayers, Cement microcracks in thin-mantle regions after in vitro fatigue loading, J Arthroplasty 19 (2004), 605-612.

[9] C. Persson, M. Baleani, L. Guandalini and M. Viceconti, The effect of gentamicin on the fracture properties of bone cement, Journal of Biomechanics 39(Supplement 1) (2006), S591-S592.

[10] A. Pustoc and L. Cheze, Normal and osteoarthritic hip joint mechanical behavior; a comparison study, Med Biol Eng Comput 47 (2009), 375-383.

[11] S.K. Bhambri and L.N. Gilbertson, Micro mechanisms of fatigue crack initiation and propagation in bone cements, Journal of Biomedical Materials Research 29 (1995), 233-237.

[12] G. Lewis, Properties of acrylic bone cement: State of the art review, J Biomed Mater Res 38 (1997), 155-182.

[13] L.D.T. Topoleski, P. Duchegne, P. Cucheyne and J.M. Cuckler, A fractographic analysis of in vivo poly(methylmethacrylate) bone cement failure mechanisms, J Biomed Mater Res 24 (1990), 135-154.

[14] B.P. Murphy and P.J. Pendergast, The relationship between stress, porosity, and nonlinear damage accumulation in acrylic bone cement, Journal of Biomedical Materials Research 59(4) (2002), 646-654.

[15] S. Benbarek, B.A.B. Bouiadjra, B.M. El Mokhtar, T. Achour and B. Serier, Numerical analysis of the crack growth path in the cement mantle of the reconstructed acetabulum, Materials Science and Engineering: C 33(Issue1) (2013), 543-549.
[16] S. Benbarek, B. Bachir Bouiadjra, A. Mankour, T. Acour and B. Serier, Analysis of fracture behaviour of the cement mantle of reconstructed acetabulum, Materials Science and Engineering: A 457(Issues 1-2) (2007), 339-385.

[17] P.Z. Nikolaus, C.K.Y. Wong and J. Tong, Fatigue failure in the cement mantle of a simplified acetabular replacement model, International Journal of Fatigue 29 (2007), 1245-1252.

[18] A. Flitti, D. Ouinas, B. Bachir Bouiadjra and N. Benderdouche, Effect of the crack position in the cement mantle on the fracture behavior of the total hip prosthesis, Computational Materials Science 49(Issue 3) (2010), 598-602.

[19] T. Achour, M.S.H. Tabetib, M.M. Bouziane, S. Benbarek, B. Bachir Bouiadjra and A. Mankour, Finite element analysis of interfacial crack behaviour in cemented total hip arthroplasty, Computational Materials Science 47(Issue 3) (2010), 672-677.

[20] B. Kim, B. Moonb, K.A. Mannc, H. Kima and K.-S. Boo, Simulated crack propagation in cemented total hip replacements, Materials Science and Engineering A 483-484 (2008), 306-308.

[21] J. Stolk, N. Verdonschot, K.A. Mann and R. Huiskes, Prevention of mesh-dependent damage growth in finite element simulations of crack formation in acrylic bone cement, Journal of Biomechanics 36 (2003), 861-871.

[22] P.E. Sinnett-Jones, M. Brown, X. Ludwig and J.Y. Buffière, Microtomography assessment of failure in acrylic bone cement, Biomaterials 33(26) (2005), 6460-6466.

[23] Pacific Research Labs. Biomed Town. https://www. biomedtown.org/

[24] Soldworks Software. Dassault System.

[25] T.P. Harrigan, J.A. Kareh, D.O. O'Connor, D.W. Burk and W.H. Harris, A finite element study of the initiation of failure of fixation in cemented femoral total hip components, Journal of Orthpaedic Research 10(Issue 1) (1992), 134-144.

[26] D.C. Wirtz, N. Schiffers, T. Pandorf, K. Radermacher, D. Weichert and R. Forst, Critical evaluation of known bone material properties to realize anisotropic FE-simulation of the proximal femur, Journal of Biomechanics 33 (2000), 1325-1330.

[27] M. Dalstra and R. Huiskes, Load transfer across the pelvic bone, Journal of Biomechanics 28(6) (1995), 715-724.

[28] F. Pauwels, Gesammelte Abhandlungen zur funktionellen Anatomie des Bewegung-sapparates. Springer Verlag, Berlin, 1965.

[29] G. Bergmann, G. Deuretzbacher, G. Heller, F. Graichen, A. Rohlmann, J. Strauss and G.N. Duda, Hip contact forces and gait patterns from routine activities, Journal of Biomechanics 34 (2001), 859-871.

[30] F. Pauwels, Atlas zur Biomechanik der gesunden und kranken Hüfte. Springer Verlag, Berlin, 1973.

[31] Abaqus 6.11 Documentation. Abaqus Analysis User's Manual, Submodeling, Section 10.2 .

[32] Abaqus 6.11 Documentation. Abaqus Analysis User's Manual, Cintour integral evaluation, Section 11.4.2.

[33] T.P. Cullelon, P.J. Pendergast and D. Taylor, Fatigue in the cement mantle of an artificial hip joint. Clinical Materials 12(Issue 2) (1993), 95-102.

[34] K.A. Mann, S. Gupta, A. Race, M.A. Miller, R.J. Cleary and D.C. Ayers, Cement microcracks in thin-mantle regions after in vitro fatigue loading, J Arthroplasty 19 (2004), 605-612. 

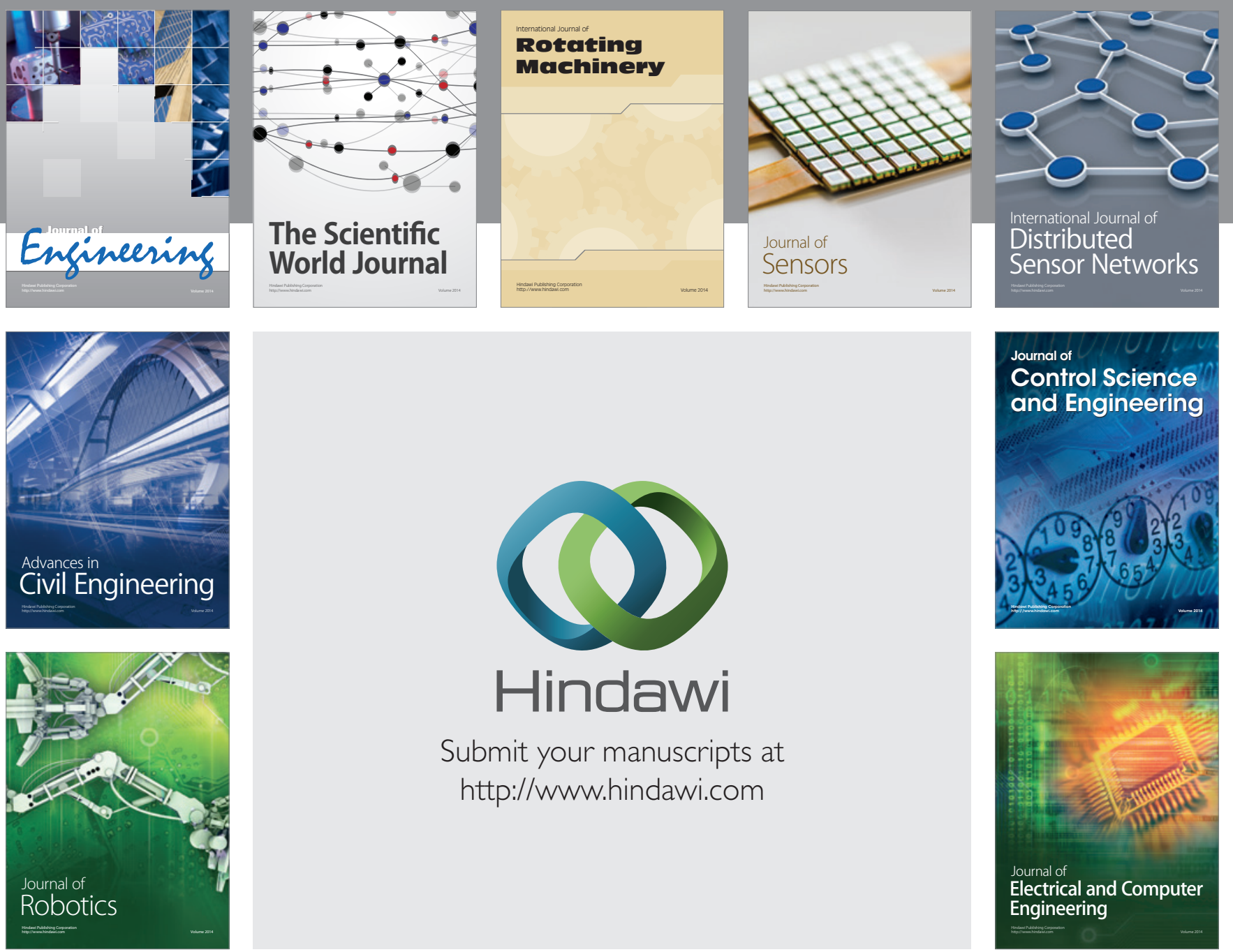

Submit your manuscripts at

http://www.hindawi.com
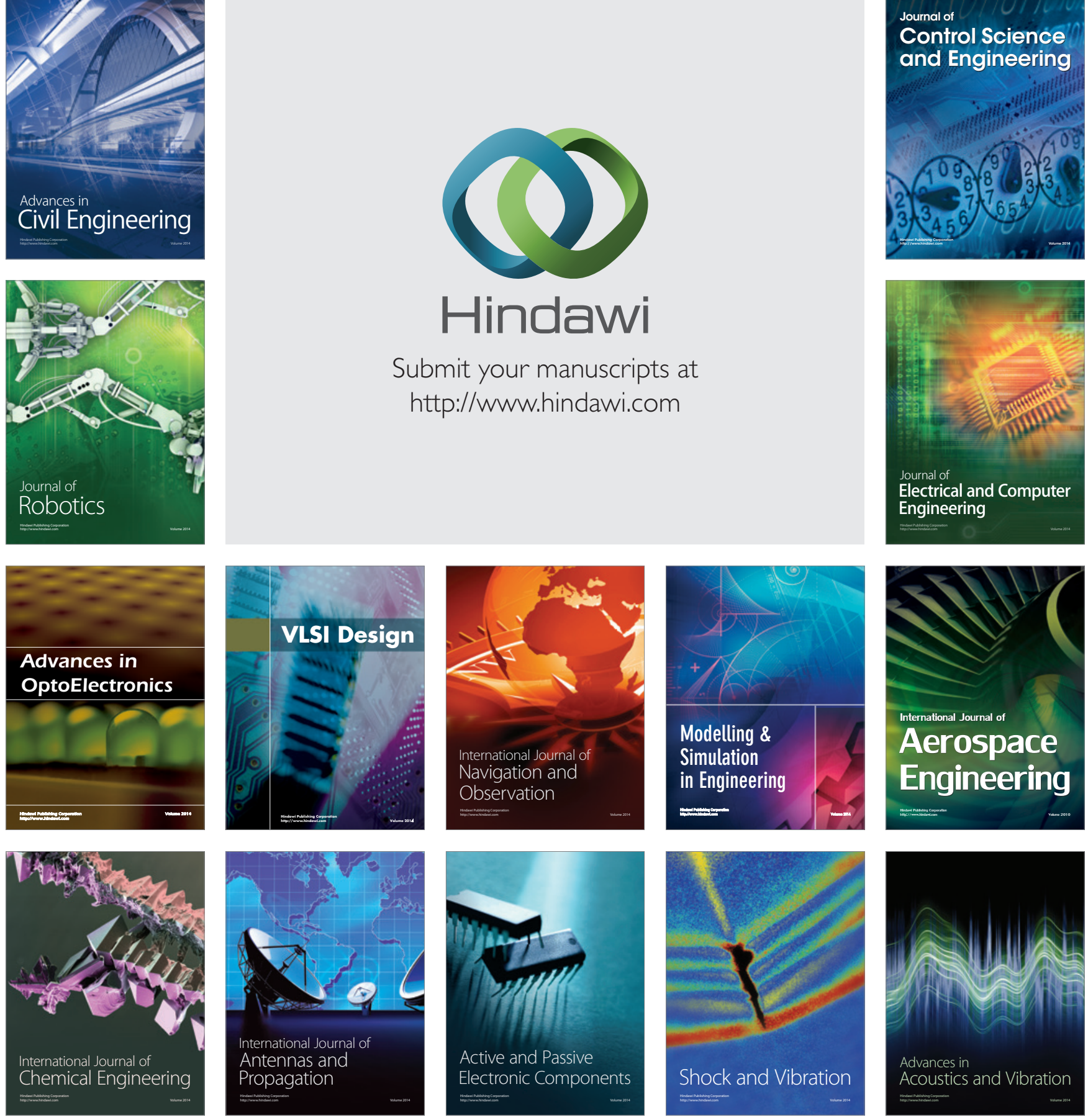